\title{
La imagen del poder regio a través de las crónicas reales impresas en el siglo XVI: El corpus de la Biblioteca de la Universidad de Oviedo
}

\author{
The image of the royal power across the royal chronicles \\ printed in the XVIth century: The corpus of the Library of \\ the University of Oviedo
}

\author{
Raquel SÁENZ PASCUAL \\ Universidad de Oviedo
}

Recibido: 16-III-2016

Aceptado: 6-VI-2016

Resumen: En la Biblioteca de la Universidad de Oviedo se conserva un conjunto de crónicas reales castellanas impresas en el siglo XVI, algunas de ellas con ilustraciones y bellas iniciales figurativas. A través de las mismas se estudia la imagen del poder regio, sus posibles fuentes de inspiración, sus precedentes e innovaciones, así como el impacto que puedan tener las prácticas de los impresores de la época. Se presta también atención a la presencia de iconografía religiosa acompañando una obra de carácter histórico y las razones de ello.

Palabras clave: Crónicas Reales, Iconografía regia, Libro impreso, Siglo XVI, Atributos del poder, Ilustraciones, Caballeros.

ABSTRACT: In the Library of the University of Oviedo there is a group of royal Castilian chronicles printed in the 16th century, some of them with illustrations and beautiful figurative initials. It allows for the study of the image of royal power, its possible sources of inspiration, its precedents and innovations, as well as the impact of the practices of the primitive printers. The presence of religious iconography in a work of historical character is also considered along with its reasons.

Keywords: Royal Chronicles, Royal iconography, Printed book, 16th century, Symbols of power, Book illustration, Knights.

La Biblioteca de la Universidad de Oviedo conserva un fondo de libros antiguos relevante por la rareza de algunos incunables, por la riqueza de algunas ediciones, o por su variedad temática, entre otros aspectos ${ }^{1}$.

\footnotetext{
${ }^{1}$ Para un mayor conocimiento de la historia y los fondos antiguos de la Biblioteca Universitaria de Ovie-
} 
Entre estos libros se encuentra un conjunto de Crónicas Reales impresas en el siglo XVI, que pueden ser de ayuda para estudiar la imagen del poder regio que existía en la España de esa época a través de sus ilustraciones y decoraciones, así como las posibles fuentes de inspiración y la continuidad o ruptura, en su caso, respecto a la imagen regia en la Edad Media.

\section{CRÓNICAS CONSERVADAS EN LA BIBLIOTECA DE LA UNIVERSIDAD DE OVIEDO}

Antes de comenzar el estudio de la imagen del poder en las Crónicas, conviene hacer un repaso de los ejemplares conservados en la Biblioteca de la Universidad de Oviedo. Proceden de la biblioteca de D. Roque Pidal, bibliófilo muy aficionado a la historia, que fue reuniendo este destacado conjunto conservado en Oviedo. Algunas de ellas, como se indicará oportunamente, a su vez procedían de la biblioteca de D. Sebastián de Soto ${ }^{2}$. El núcleo fundamental son las di-

do, véase R. RODRÍGUEZ ÁLVAREZ, La Biblioteca de la Universidad de Oviedo, 1765-1934, Oviedo, 1993; ÍDEM, Tesoros Bibliográficos de Asturias. Oviedo, 1998; “El fondo histórico de las bibliotecas universitarias españolas. El fondo de la biblioteca de la Universidad de Oviedo", en R. RODRÍGUEZ, M. LLORDÉN (eds.), El libro antiguo en las bibliotecas españolas, Gijón, 1998, pp. 111-135; ÍDEM, Las horas de los libros. El esplendor de las colecciones bibliográficas asturianas. Catálogo de Exposición, Oviedo, 2009; J. L. PÉREZ DE CASTRO y R. RODRÍGUEZ ÁLVAREZ, "Don Roque Pidal y la reconstrucción de la Biblioteca de la Universidad de Oviedo", en Actas del II Congreso de Bibliografía Asturiana, Granda-Siero, 1999, pp. 969-1026. Para realizar este estudio ha sido fundamental consultar el catálogo y fichero del fondo antiguo de la Biblioteca Universitaria de Oviedo. Agradezco al Sr. Director de la misma, D. Ramón Rodríguez, a Dª Ángeles Llavona así como al personal de la Central las facilidades ofrecidas para poder llevar a cabo este trabajo.

${ }^{2}$ Tras la destrucción de la biblioteca universitaria en 1934 fueron varias las acciones llevadas a cabo para su reconstrucción. Entre ellas resultó fundamental la oferta que realizó D. Roque Pidal para vender en condiciones ventajosas su rica biblioteca. Sobre este aspecto J. L. PÉREZ DE CASTRO y R. RODRÍGUEZ, Op. cit. Para la biblioteca de los Soto véase R. RODRÍGUEZ ÁLVAREZ, ferentes ediciones de crónicas reales de monarcas castellanos, aunque se completó con algunas de monarcas de otros reinos, como la de Jaime $\mathrm{I}^{3}$. Igualmente se pueden encontrar, por ejemplo, crónicas de carácter más amplio sobre la historia del reino de Casti$1 a^{4}$. El estudio se centra en las crónicas reales castellanas. Esta colección de Oviedo puede considerarse como una muestra significativa de este tipo de publicaciones del siglo XVI y da pie a un estudio más amplio en el futuro.

Se podría iniciar este apartado siguiendo un criterio cronológico respecto al texto original de la crónica, puesto que se trata de analizar la imagen que acompaña al texto, pero se va a optar por seguir, en la medida de lo posible, la cronología de las ediciones impresas conservadas.

El ejemplar más antiguo de esta colección corresponde a la Crónica de Juan II impresa por Arnao Guillén de Brocar en Logroño, el 10 de octubre de $1517^{5}$. El texto se atribuye a Fernán Pérez de Guzmán y la corrección a Lorenzo Galíndez de Carvajal.

Dos bibliófilos asturianos del siglo XIX: Felipe de Soto Posada y Sebastián de Soto Cortés, Oviedo, 2002.

${ }^{3}$ De la Crónica de Jaime I, de Ramón Muntaner, se conservan dos ejemplares: una edición de la viuda de Ioan Mey Flandro publicada en Valencia en 1558 (Biblioteca de la Universidad de Oviedo, en adelante BUO, CGR-440) que cuenta con portada con escudo real e iniciales figurativas, y la edición de Iaume Cortey en Barcelona, 1562 (BUO, CGR-617), sin ilustraciones, salvo las decoraciones de la portada. También se conserva una crónica del rey San Luis de Francia publicada en Toledo en 1567 por Francisco de Guzmán (BUO, CGR318).

${ }^{4}$ Se puede citar, como ejemplos de crónicas de carácter más general, Las cuatro partes enteras de la crónica de España de Alfonso X el Sabio, impresa en Zamora en 1541 por Agustín de Paz y Juan Picardo (BUO, A-372) (portada con escudo imperial de Carlos V) o la Crónica de España abreviada de Diego de Valera, publicada en Sevilla por Juan Cromberger en 1538 (A-353), acompañada con imágenes de monarcas.

${ }^{5}$ BUO, CGR-476. Como curiosidad, en la portada aparece manuscrito el nombre de Gaspar Abbat de Espejo. Este ejemplar perteneció a D. Roque Pidal y todavía conserva una etiqueta de la librería de Gabriel Sánchez de la calle Carretas de Madrid. 
Fue prologada por Alvar García de Santamaría. En el título se señala que se imprimió "por mandado del católico rey don Carlos su visnieto" y con privilegio; es una muestra de la revitalización de este género histórico en época del emperador. Esta obra es especialmente rica en su decoración por la calidad de sus xilografías, su complejidad iconográfica y el número de imágenes. Algunas de ellas, como la escena del Calvario, va firmada con las iniciales ID (Juan de Vingles) ${ }^{6}$.

La Biblioteca cuenta con otra edición de la Crónica del Serenissimo Rey Juan II, de Fernán Pérez de Guzmán, esta vez impresa en Sevilla en 1543 por Andrés de Burgos, y encargada por Pedro y Diego Ximénez, mercaderes de libros $^{7}$, y otra impresa por Porralis en Pamplona, en $1591^{8}$, que sigue, como señala el propio ejemplar, el texto de la publicada por Brocar en 1517, no así sus imágenes.

De las Crónicas del Canciller Ayala se conservan en esta biblioteca tres ejemplares antiguos, dos de ellos impresos en el siglo XVI corresponden a los publicados por Jacome Cromberger en Sevilla, en $1549^{\circ}$, y por Pedro Porralis en Pamplona, en $1591^{10}$; hay

\footnotetext{
${ }^{6}$ Sobre la ilustración en los trabajos de Brocar, por ejemplo, C. RODRÍGUEZ PELAZ, "La ilustración en los impresos de Guillén de Brocar", Ondare, nº 17, 1998, pp. 437-445. También A. ODRIOZOLA, "Obras impresas en Logroño por Arnao Guillén de Brocar", Bibliografía Hispánica, no 2, 1943, pp. 22-37; J. M. LOPE TOLEDO, “La imprenta en La Rioja", Berceo, LVI, 1960, pp. 313-330, especialmente p. 323 .

${ }^{7}$ BUO, CGR-457. Se trata de un ejemplar procedente de la Biblioteca del Conde de Toreno, un benefactor de la biblioteca universitaria.

${ }^{8}$ BUO, CGR-460. Procede de la biblioteca de D. Roque Pidal.

${ }^{9}$ BUO, CGR-430. Este ejemplar procede de la Biblioteca de D. Felipe de Soto a través de la venta que D. Roque Pidal hizo a la Biblioteca Universitaria de Oviedo en 1935, como evidencia el sello oval de estampilla con la marca "F. Soto" en el reverso del fol. CXCIIII. Sobre esta venta véase J. L. PÉREZ DE CASTRO y R. RODRÍGUEZ ÁLVAREZ, Op. cit., p. 970. Es un ejemplar foliado, impreso a doble columna y con letra gótica. Carece de encuadernación pero conserva la portada.
}

${ }^{10}$ BUO, CGR-429. un ejemplar muy posterior, el de la edición de Llaguno Amírola publicado por De Sancha en Madrid, en $1779^{11}$. Los ejemplares del siglo XVI responden, como señala Orduna, a reediciones del incunable publicado en Sevilla en 1495 por Meinardo Ungut y Estanislao Polono ${ }^{12}$.

De Juan Núñez de Villaizán se conserva la Chronica del muy esclarescido principe y rey $D$. Alfonso el Onzeno, impresa en Valladolid en enero de 1551 por Sebastián Martínez a costa de Pedro de Espinosa y Antonio de Zamora ${ }^{13}$. La obra se compuso en la primera mitad del s. XIV. Este ejemplar además incluye otras tres crónicas reales impresas en 1554 por el propio Martínez: las de Alfonso X, Sancho IV y Fernando IV. Existe en la biblioteca otro volumen que recoge sólo las de Alfonso X y Sancho IV de la misma edición ${ }^{14}$.

${ }^{11}$ BUO, CGVII-23. El ejemplar de Llaguno es de gran interés por ser una edición que fue muy cuidada en el repertorio de sus fuentes y que pretendía lograr un texto fiel al del Canciller, lo que implicó un destacado trabajo de investigación, incluyendo la consulta de las notas de D. Jerónimo Zurita. Va ilustrada con magníficos grabados de los monarcas con diseño de Antonio Carnicero, pero que sobrepasan el marco cronológico de este estudio. Perteneció a la biblioteca de D. Felipe de Soto Posada. Este ejemplar supone un complemento particularmente interesante a las Crónicas del Canciller impresas en el s. XVI que se conservan en Oviedo.

${ }^{12}$ A estas dos reediciones se suman las de Ramón Petras en Toledo en 1526 y la del propio Juan Cromberger en Sevilla en 1542. La obra había tenido también difusión como libro manuscrito, de manera que Orduna indica la existencia de 24 testimonios manuscritos. G. ORDUNA, "Pedro López de Ayala", en Diccionario Filológico de Literatura Medieval Española. Textos y transmisión, Madrid, 2002, pp. 878-885, especialmente pp. 878-880. El códice de la British Library ms Add. 17906 (s. XV) muestra al rey Enrique III a caballo con espada y escudo (p. 882); también el manuscrito 1798 de la Biblioteca Nacional de Madrid tiene miniaturas.

${ }^{13}$ BUO, CGR-454. El ejemplar todavía conserva una etiqueta de la biblioteca de la Condesa de Bornos. De esta crónica de Núñez de Villaizán existe otra edición posterior impresa por Pedro Rodríguez en Toledo, en 1595 (BUO, CGR-464), cuya portada muestra las armas del rey Felipe II y sólo cuenta con iniciales ornamentales.

${ }^{14} \mathrm{BUO}, \mathrm{CGR}-446$. 
La Chronica de los muy altos y esclarecidos Reyes Catholicos la imprimió Sebastián Martínez en Valladolid, en $1565^{15}$. El ejemplar que se conserva en la biblioteca universitaria es mútilo, si bien se ha procurado completar lo que le falta con una copia manuscrita; por esa razón no contamos con portada, por ejemplo. En el resto de la edición no hay ilustraciones, sólo han llegado iniciales figurativas que muestran a parejas de niños jugando, sin escenas históricas o trascendentes. Existe además un ejemplar impreso de las Adiciones a las Crónicas de los Reyes Católicos, publicado en Zaragoza por Juan Millán en $1567^{16}$. Este ejemplar aragonés destaca por la riqueza de sus xilografías, con escenas de lucha: un ejemplo de reaprovechamiento de los tacos en las imprentas hispanas.

Se conserva también una interesante edición de la Crónica de Fernando III impresa por Francisco del Canto en Medina del Campo, en $1568^{17}$. El ejemplar perteneció anteriormente a la biblioteca de D. Felipe de Soto, quien en nota manuscrita atribuía las notas marginales de la crónica a Diego de Colmenares, historiador de Segovia. En ellas se recogen informaciones como que son cuatro las crónicas de reyes que se incluyen en la obra (Fernando III, Alfonso el Sabio, Sancho el Bravo y Fernando el Emplazado). En una de las anotaciones se plantea como hipótesis que el autor de la

${ }^{15}$ BUO, CGR-435. Según aparece en anotación manuscrita, esta obra perteneció a "D. Man(ue)l. De Acosta, Relator". Además de completar el texto impreso perdido, las anotaciones manuscritas dan información sobre el autor de la crónica y las hipótesis que se hicieron sobre él, pues, si bien en el ejemplar aparece como obra de Antonio de Nebrija, el autor fue Hernando del Pulgar. En la BUO también se conservan varios ejemplares de la traducción latina que hizo de esta obra Nebrija, publicada en Granada en 1545, pero no tienen ilustraciones (BUO, CGR-452, CGR-475, CGR-478).

${ }^{16}$ BUO, CGR-465. A. MILLARES CARLO, Libros españoles y portugueses del siglo XVI, impresos en la península o fuera de ella, Madrid, 1977, pp. 302-303, nº 201.

${ }^{17} \mathrm{BUO}, \mathrm{CGR}-444$ crónica de Fernando III fuese D. Diego López, arcediano de Sevilla ${ }^{18}$.

Y para cerrar este repaso por las Crónicas conservadas en la BUO no podemos olvidar la obra de Esteban de Garibay ya avanzado el s. XVI, un concepto totalmente diferente de enfrentarse a la narración en el aspecto historiográfico y en lo que se refiere a la ilustración del texto. Su obra, Los XL libros del Compendio Historial de las Crónicas y universal Historia de todos los Reynos de España, en 4 volúmenes, fue publicada en Amberes, en la imprenta de Plantino, en $1571^{19}$. No existe imagen figurativa como en las crónicas de origen medieval, se ha optado por una portada principal de tipo arquitectónico -donde se recoge el título de la obra y se adorna con pequeños escudos vinculados al autor-, y una serie de portadas decorativas con marcos correiformes o elementos formando panoplias en cuyo interior se cobijan los escudos de los reinos estudiados.

\section{LA IMAGEN DEL PODER REGIO EN EL RENACIMIENTO A TRAVÉS DE LAS ILUSTRACIONES DE LAS CRÓ- NICAS DE LA BUO}

Son varias las maneras en que aparecen representados los monarcas en estas obras. En todas ellas podemos saber que se trata de la representación de un monarca porque le acompañan símbolos que aluden a su

${ }^{18}$ Se atribuye a Diego López de Cortegana o de Cartagena (1455-1524) la edición de una Crónica de Fernando III publicada por Jacobo Cromberger en Sevilla, 1516. Al parecer era una edición que partía de un texto del Arzobispo Rodrigo Ximénez de Rada, De rebus Hispaniae, con añadidos posteriores. Véase M. I. HERIZO, "Crónica del Santo Rey D. Fernando III: un postincunable único", Folio Complutense, (en línea) 16 Marzo 2012, consultado el 14 junio de 2014. URL: http://biblioteca.ucm.es/blogs/ Foliocomplutense/5562.php\#.V31Cr1SLTIV.

${ }^{19}$ BUO, CGR-471 a 474. Esta extensa obra perteneció a la biblioteca de D. Felipe de Soto. En el primer tomo se incluye un retrato del autor, el único en la obra. Las iniciales que encabezan los diferentes apartados son de carácter decorativo, de gran belleza y se pueden encontrar en otras obras de diferente temática surgidas de las prensas plantinianas. 
dignidad. Estas obras fueron publicadas en el siglo XVI, si bien buena parte de ellas se escribieron en los siglos medievales. Surgen las preguntas: las representaciones de estos monarcas, ¿se pueden poner en relación con la iconografía medieval del poder regio?; ¿cuáles son los símbolos que adornan la figura regia?; ¿se puede hablar de novedades iconográficas en las crónicas reales impresas durante el siglo XVI?

Los atributos tradicionales del poder regio están ampliamente representados en las xilografías de estas obras. Como señala Raynaud, los elementos tradicionales que caracterizan a los reyes son la corona, el cetro y la indumentaria heráldica; en el caso castellano hay que añadir la espada ${ }^{20}$. En efecto, desde época antigua las monarquías hispanas ostentaron símbolos e insignias emblemáticas que indicaban su condición regia. Estas insignias de poder pervivieron a lo largo de los siglos y no son ajenas a las que se encuentran en el resto de Europa ${ }^{21}$. La más habitual

${ }^{20}$ C. RAYNAUD, "La représentation du pouvoir dans le langage iconographique de l'enluminure française au début du XVème siècle", en Images et Pouvoirs, París, 1993, pp. 215-231, especialmente p. 216.

${ }^{21}$ I. BANGO TORVISO, "La imagen pública de la realeza bajo el reinado de Alfonso X. Breves apostillas sobre regalia insignia y actuaciones protocolarias", Alcanate, VII, 2010-2011, pp. 13-42, especialmente p. 13. Son muchas las publicaciones que insisten en este aspecto, por citar algunas de ellas y sin ánimo de exhaustividad, V. CARDERERA Y SOLANO, Iconografía española: colección de retratos, estatuas, mausoleos y demás monumentos inéditos de reyes, reinas, grades capitanes, escritores, etc., desde el siglo XI hasta el siglo XVII, Madrid, 1864; P. E. SCHRAMM, Las insignias de la realeza en la Edad Media española, Madrid, 1960; B. PALACIOS MARTÍN, “Los símbolos de la soberanía en la Edad Media española. El simbolismo de la espada", en VII Centenario del Infante D. Fernando de la Cerda, Madrid, 1976, pp. 272-296; J. M. NIETO SORIA, “Imágenes religiosas del rey y del poder real en la Castilla del siglo XIII", En la España Medieval V, no 2, 1986, pp. 709-729; J. YARZA LUACES, "La imagen del rey y la imagen del noble en el s. XV castellano", en A. RUCQUOI (coord.), Realidad e imágenes del poder. España a fines de la Edad Media, Valladolid, 1988, pp. 267291; J. M. NIETO SORIA, "Del rey oculto al rey exhibido: Un síntoma de las transformaciones políticas en la Castilla Bajomedieval", Medievalismo, no 2, 1992, pp. 5-28; A. RUCQUOI, “De los reyes que no son taumatur- es la corona, y la mayoría de las imágenes la recogen. La excepción es el caso de unas xilografías ecuestres que muestran a caballeros armados, pero sin corona, y proceden de obras de otros géneros; son imágenes reaprovechadas, concretamente de libros de caballería, como en el caso de las Crónicas del Canciller impresas por Porralis en 1591.

El segundo atributo más destacado es el de la espada, especialmente entre los monarcas castellanos, si bien esta puede variar en su significación. Algunos autores llegan a considerar fundamental esta insignia de poder en relación con los reyes hispanos. Se habría asociado la espada con el derecho de conquista y se habría convertido en símbolo de soberanía, ya fuese en imágenes ecuestres o en imágenes sedentes del monarca ${ }^{22}$. Vinculada con la espada está la ceremonia de

gos: los fundamentos de la realeza en España", Relaciones. Estudios de Historia y Sociedad, XIII, 1992, pp. 55-100; C. DELGADO VALERO, "La corona como insignia de poder durante la Edad Media", Anales de la Historia del Arte, no 4, 1994, pp. 747-763; J. YARZA LUACES, “Imágenes reales hispanas en el fin de la Edad Media", en E. RAMÍREZ VAQUERO (ed.), Poderes públicos de la Europa medieval. Principados, reinos y coronas, Pamplona, 1997, pp. 441-500; O. PÉREZ MONZÓN, “Iconografía y poder real en Castilla: las imágenes de Alfonso VIII", Anuario del Departamento de Historia y Teoría del Arte, XIV, 2002, pp. 19-41, señala esta autora que el tipo de imagen militar del monarca es una referencia a su carácter victorioso desde la Antigüedad (especialmente. p. 22); D. CHAO CASTRO, "Aproximación a la iconografía de poder de los reyes Trastámara en Castilla", en Image et Pouvoir: Actes du 4e Congrès International du GTIMH, Lyon, 2006, pp. 85-98. F. VILLASEÑOR SEBASTIÁN, "La legitimación del poder real: Imágenes iluminadas de los monarcas en la Castilla Trastámara", en XIII Jornadas Internacionales de Historia del Arte. Arte, Poder y Sociedad en la España de los siglos XV a XX, Madrid, 2008, pp. 139-144.

22 B. PALACIOS MARTÍN, Op. cit., pp. 272-296. La importancia destacada del símbolo de la espada en relación a la corona, con mayor peso en otros países europeos, se debería a la propia evolución histórica de los reinos hispanos y las "peculiares" relaciones con el Papado (especialmente pp. 280-285). Posteriormente F. GUTIÉRREZ BAÑOS, Las empresas artísticas de Sancho IV el Bravo, Burgos, 1997, p. 67 o T. F. RUIZ, "The Symbolic Meaning of Sword and Palio in Late Medieval and Early Modern Ritual Entries: The Case of Seville", Memoria y Civilización, 12, 2009, pp. 13-48. 
armar caballero al monarca, como planteaba ya Alfonso X el Sabio, con lo que la xilografía del caballero en un contexto de crónica real, aunque sea reaprovechada, resulta una elección afortunada. Chao Castro señala que es el símbolo de la obediencia al rey, símbolo de las cuatro virtudes cardinales y alude a la condición guerrera del monarca, por lo que refleja bien la idea del poder regio, según se aprecia tanto en algunas miniaturas como en muchos sellos desde la plena Edad Media ${ }^{23}$. Por otra parte, la espada también simboliza la justicia, que no sólo es una de las virtudes cardinales, sino también una de las funciones fundamentales de la realeza, estrechamente relacionada, además, con la justicia divina ${ }^{24}$.

Otro de los atributos es el manto regio, que no siempre aparece en las xilografías que representan a los monarcas coronados en los ejemplares estudiados. El trono con o sin pedestal es otra de las grandes insignias del poder, pero no aparece en todas las crónicas de la biblioteca universitaria.

En las crónicas estudiadas, además de la variedad de insignias regias, también se pueden encontrar diferentes modelos de

${ }^{23}$ D. CHAO CASTRO, Op. cit., pp. 90-91.

${ }^{24}$ J. M. NIETO SORIA, "Imágenes religiosas del rey....", pp. 720-721; E. H. KANTOROWICZ, Los dos cuerpos del rey. Un estudio de teología política medieval, Madrid, 1985, pp. 93-187; J. M. NIETO SORIA, “Origen divino, espíritu laico y poder real en la Castilla del siglo XIII", Anuario de Estudios Medievales, no 27,1997 , pp. 43-101, especialmente pp. 65-67. Sobre el aspecto del simbolismo de la espada y la justicia vinculada a la realeza véase también G. CAVERO DOMÍNGUEZ, E. FERNÁNDEZ GONZÁLEZ y F. GALVÁN FREILE, "Imágenes reales, imágenes de justicia en la catedral de León", e-Spania (en línea), no 3, 2007, consultado el 16 de septiembre de 2015. URL: http://e-spania.revues. org/204; En relación a las peculiaridades del concepto de realeza en los reinos hispanos, T. F. RUIZ, "Une royauté sans sacre: la monarchie castillane du bas Moyen Âge", Annales. Économies, Sociétés, Civilisations, no 3, 1984, pp. 429-453; A. RUCQUOI, "De los reyes que no son ...", F. PAVÓN CASAR, La imagen de la realeza castellana bajomedieval en los documentos y manuscritos, Tesis doctoral defendida en la Universidad Complutense, Madrid, 2009. URL: http://eprints.ucm.es/9313/1/ T31084.pdf, entre otros. representación del monarca. Existen muy pocas escenas narrativas en estas ilustraciones conservadas en Oviedo; son más bien supuestos retratos, en absoluto fidedignos, que vienen a representar más la dignidad regia que al individuo. Los tipos más sencillos son los que muestran al monarca de pie, solo, con sus insignias de poder. Además, encontramos el tipo del monarca entronado, solo o acompañado, que es la imagen de la majestad regia; y por último, pero no menos interesante, el retrato regio ecuestre.

Una de las representaciones básicas que aparece en estas obras es la del monarca de pie, con armadura, coronado y con espada, que vemos en las Crónicas del Canciller Ayala, publicadas en Sevilla en 1549 por los Cromberger ${ }^{25}$. La figura del monarca, de tres cuartos y posición frontal, va completamente armada, incluso con los guanteletes. Con su mano izquierda sujeta un escudo y con la derecha una espada que cruza ante su pecho. Va coronado. Sobre su cabeza se ha escrito la identificación de la figura: "El rey don Enri$q^{\prime \prime}$ ". El escudo alargado que sostiene en la mano está decorado con motivos heráldicos: es cuartelado, representando el primero y el cuarto una luna, el segundo y el tercero barras. Estas armas no se corresponden con las de D. Enrique de Trastámara. El estilo es claramente retardatario respecto a la fecha de edición. A ambos lados del monarca hay dos fajas verticales: la de la izquierda lleva en el centro el escudo partido de Aragón y Aragón-Sicilia flanqueado por el yugo y las flechas, emblemas de los Reyes Católicos y, por tanto, un añadido totalmente ajeno a la figura del efigiado por ser posterior; la de nuestra derecha muestra unos adornos florales flanqueando un escudo heráldico con una banda en el centro y una cadena en la bordura ${ }^{26}$.

\footnotetext{
${ }^{25}$ BUO, CGR-430. Fol. CXVIr.
}

${ }^{26}$ Quizás una referencia a la orden de la Banda. A. FERNÁNDEZ DE CÓRDOVA, "El emblema de la Banda entre la identidad dinástica y la pugna política en la Castilla bajomedieval (c. 1330-1419)", Emblemata, no 20-21, 2014-2015, pp. 121-170. 
En el inicio de la siguiente crónica, la del rey Juan I, la imagen del monarca que se dispone es exactamente la misma, tanto en la figura del rey como en las dos fajas que lo flanquean con la heráldica de los Reyes Católicos. Sólo se ha cambiado la identificación del monarca: "El rey don Juan". Es evidente que es un taco xilográfico reaprovechado, práctica habitual entre los impresores de la época ${ }^{27}$. Lo importante es que se trata de mantener el concepto, la dignidad regia, aunque no sea un retrato fidedigno ni individual del monarca.

Resulta interesante la localización de ambas imágenes en relación con el texto de sus crónicas. El editor prefirió posponer la imagen real de Enrique II (fol. CXVIr.) hasta que alcanzó el trono, aun cuando esto suponga retrasar hasta ocho capítulos la imagen decorativa y representativa más importante con la que cuenta el texto: no es el primer año de la Crónica de este monarca pero sí de su reinado tras el conflicto armado con su hermano D. Pedro I y la muerte violenta de éste. En cambio, la imagen del rey D. Juan se ha optado por disponerla en el inicio de la crónica, bajo el título del capítulo I. Es una transición de padre a hijo pacífica, lo que pudiera explicar esta situación.

Una variante de este tipo es la imagen del monarca de pie, con sus atributos de poder pero sin armadura. La encontramos, por ejemplo, en una inicial, la letra E, de la Crónica de Juan II (Brocar, Logroño, 1517) ${ }^{28}$. El monarca, vestido con indumentaria que corresponde a la época del libro -se aprecia perfectamente en el calzado achatado-, porta corona, con la mano izquierda sostiene un

\footnotetext{
${ }^{27}$ BUO, CGR-430, Juan I en fol. CXXXVIr. También aparecía esta misma figura identificada como Floristán en la obra de Juan Díaz, Lisuarte de Grecia, publicada por los Cromberger en Sevilla en 1526. J. M. LUCÍA MEGÍAS, Imprenta y libros de caballerías, Madrid, 2000 pp. 243-244. Esta figura también aparece repetida para varios monarcas en la Crónica de España de Diego de Valera, publicada por Cromberger en 1538 (BUO, A-353).

${ }^{28}$ BUO, CGR-476. Aparece en más de una ocasión, por ejemplo en fol. LIIIr.
}

orbe y con la derecha una espada ${ }^{29}$. Se dispone en el Prefacio de la Crónica, un buen ejemplo de uso de inicial adecuada por su decoración al texto. Se repite a lo largo de la crónica. De hecho en esta elaborada edición de Brocar no es la única inicial con figuración del monarca: perteneciente al mismo juego se ha dispuesto la letra $G$ con un monarca entronado, de nuevo con los atributos regios $\mathrm{y}$, en este caso, con la identificación como rey D. Juan II. Si la primera inicial aparecía en el prólogo, en esta ocasión aparece en el inicio del texto de la crónica del monarca.

Otro tipo de la imagen del poder del rey es la del monarca entronado, habitualmente acompañado de todos o varios de los atributos de su poder. Es la imagen de la majestad real, posiblemente la que mejor lo defina. Algunas de las crónicas conservadas en la biblioteca universitaria cuentan con esta imagen, bien en la portada de la obra, bien entre sus páginas, o en alguna inicial.

La Crónica de Juan II (1517), la de mayor riqueza y variedad iconográfica entre las estudiadas, muestra en su portada una espléndida xilografía en la que aparece el rey entronado, con corona y cetro, revestido con armadura y amplio manto, recibiendo a dos hombres que, arrodillados ante él, le ofrecen un libro abierto (Fig.1). Varios aspectos destacan de esta imagen: en primer lugar la actitud de los dos hombres, uno de los cuales, seglar, ha dejado su bonete sobre el suelo en evidente señal de respeto; el monarca, separado con claridad de ambos, está sobre un elevado escaño, marcando aún más ese sentido mayestático; la filacteria que rodea al monarca potencia más si cabe ese distanciamiento físico respecto a los portadores del libro y al propio lector; el trono es un elemento arquitectónico que resulta, en este caso, monumental por sus dimensiones y sobriedad. En él sólo se permite una licencia decorativa,

\footnotetext{
${ }^{29}$ Otra variable en este juego de iniciales es la letra E con que se comienza el capítulo del segundo año de reinado de D. Juan (fol. XIVr.): es algo más sencilla que la anterior, ya que el monarca sólo porta corona y espada. Es una inicial que se repite en la edición.
} 


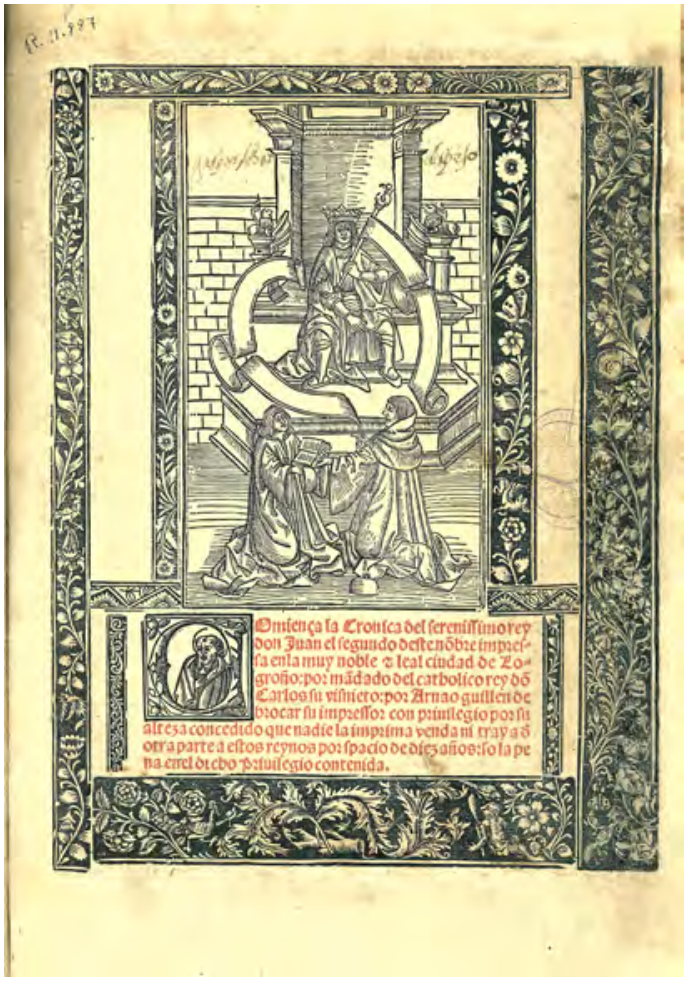

- Fig. 1. Fernán Pérez de Guzmán. Crónica del Serenísimo Rey Juan II, impresa por Arnao Guillén de Brocar, Logroño, 1517. Portada. Biblioteca de la Universidad de Oviedo, Signatura CGR476. Foto BUO.

que no es casualidad: en los brazos del mismo figuran sendos leones, imagen también vinculada a los monarcas por su simbolismo como rey de las fieras, según el Fisiólogo, y que cuenta con numerosos precedentes.

Particularmente interesante en la tipología del monarca entronado es la Crónica de Fernando III impresa en $1568^{30}$ (Fig. 2), pues presenta una portada compuesta en la que se disponen dos monarcas sedentes con sus atributos de poder. No se trata en este caso de tronos destacados arquitectónicamente: de hecho, en el de la derecha lo más notorio es su basa ornamentada, mientras que el otro se limita a aparecer con un paño de honor brocado. En ambos casos, los monarcas visten armadura, manto sobre sus hombros, corona en sus cabezas, sosteniendo la espada desnuda en alto y un escudo con las armas de Castilla y León. El monarca de nues-

\footnotetext{
${ }^{30}$ BUO, CGR-444, fol. I r.
}

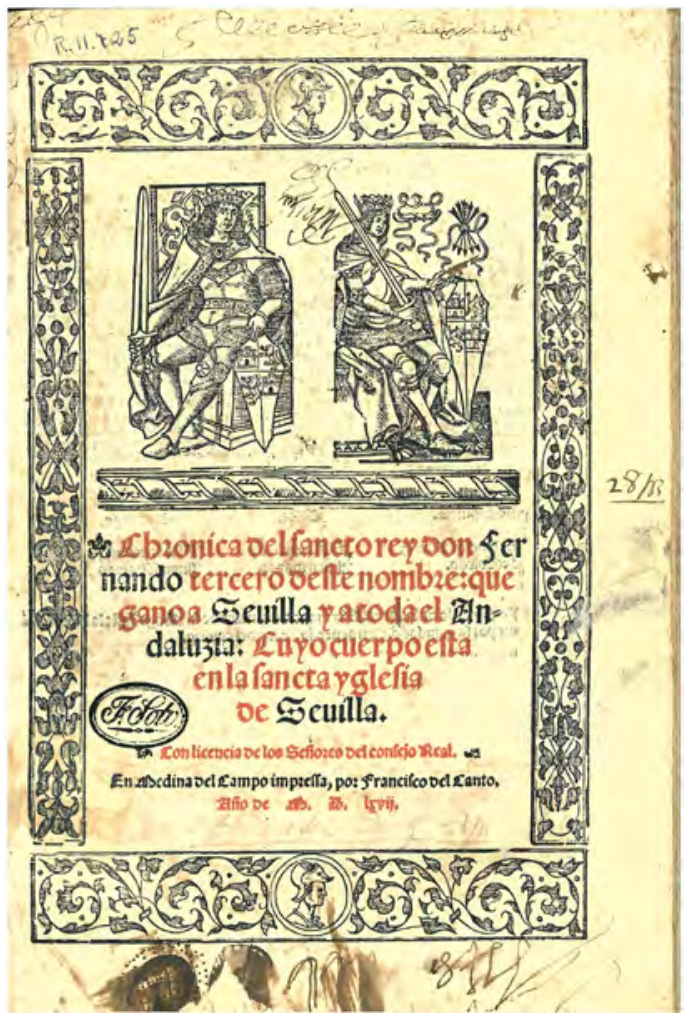

- Fig. 2. Crónica del Santo Rey D. Fernando III, impresa por Fernando del Canto, Medina del Campo, 1568. Portada. Biblioteca de la Universidad de Oviedo, Signatura CGR-444. Foto BUO.

tra derecha va acompañado en un lateral por el yugo y las flechas, algo que no aparece en el de nuestra izquierda, por lo que se le identifica como Fernando el Católico; el peinado, incluso, acompañaría a su época. Al monarca de la izquierda se la ha identificado, por su parte, con Fernando III el Santo ${ }^{31}$.

Cabe llamar la atención sobre el monarca de nuestra izquierda ya que parte del mismo modelo que el dibujo coloreado en un manuscrito de la Biblioteca Nacional de las Crónicas del Canciller Ayala, el Mss. 7441, Crónica del Muy Alto y muy Excelente Príncipe el Rey Don Enrrique el Doliente ordenada por Don Pedro López de Ayala Canciller mayor de Castilla Año de MCCCXCVI, un ejemplar que contiene una sola ilustración que decora su portada (Fig. 3) ${ }^{32}$. Organizada en dos par-

\footnotetext{
${ }^{31}$ A. MILLARES CARLO, Op. cit., p. 122.

${ }^{32}$ Según la información del catálogo de la Biblioteca Nacional de España (en adelante BNE), el manuscrito
} 


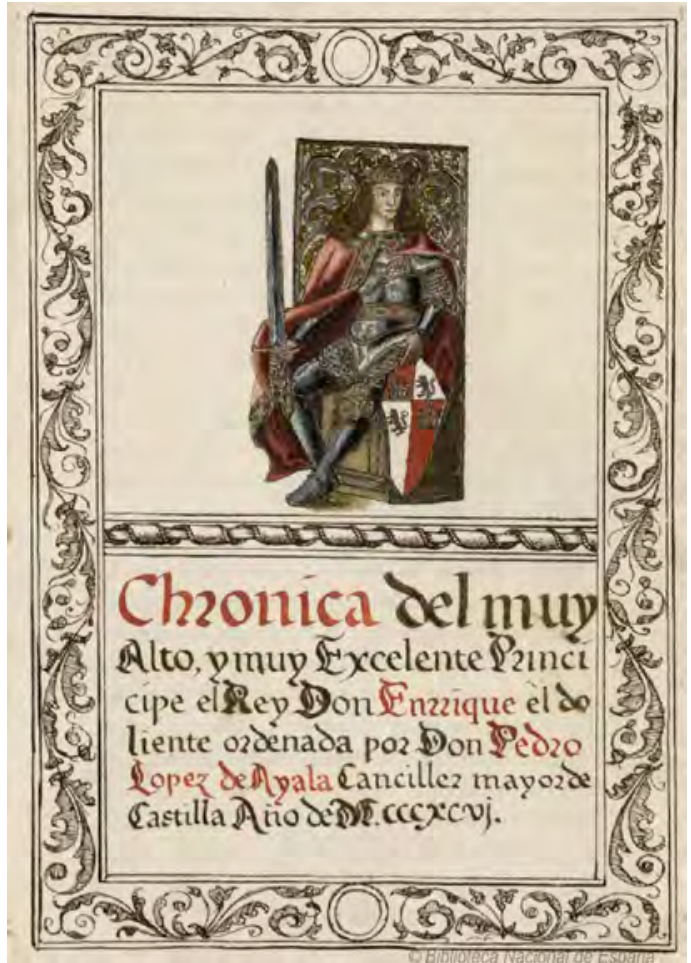

- Fig. 3. Pedro López de Ayala. Crónica del muy alto y muy excelente príncipe el Rey Don Enrique el Doliente. Detalle de la portada. Biblioteca Nacional de España, Mss 7441. Foto BNE (URL: http://bdh-rd.bne.es/viewer. vm?id=0000145197\&page $=3$ )

tes, en la superior aparece la imagen y en la inferior el título a dos tintas, ambas separadas por una greca que consiste en una vara rodeada de una cinta -motivo fácilmente localizable en el libro impreso-, y todo ello enmarcado por una delicada greca vegetal. Las xilografías de los monarcas, son, lógicamen-

procede del Convento de San Martín de Madrid, se fecha en el s. XVI y la crónica se ha continuado al final por un anónimo. Sobre este ejemplar, G. ORDUNA, “Nuevo registro de códices de las crónicas del Canciller Ayala. 2a parte", Cuadernos de Historia de España, LXV-LXVI, 1981, pp. 155-206, especialmente pp. 180181 , señala que el folio donde va el título con el dibujo coloreado corresponde a los añadidos en la encuadernación -pergamino con cierres de piel- y no a la copia del manuscrito. La letra de la copia responde al s. XVI. Hay numerosas copias manuscritas de las Crónicas del Canciller realizadas, sobre todo, durante los siglos XV y XVI, pero sin apenas decoración. Véase también ÍDEM, "Nuevo registro de códices de las crónicas del Canciller Ayala", Cuadernos de Historia de España, LXIII-LXIV, 1980, pp. 218-255. te, anteriores a la edición impresa del libro. Incluso podemos observar similitudes entre ambos ejemplares en cuanto a la organización de esa portada, más allá de la imagen regia.

El dibujo coloreado de la $\mathrm{BNE}^{33}$ y la xilografía de la edición de Francisco del Canto coinciden hasta el más mínimo detalle de la ornamentación de la armadura o del plegado del manto, incluso de la decoración de brocado del trono. Es un perfecto ejemplo de esas estrechas relaciones entre las imágenes de las obras manuscritas y las impresas a fines de la Edad Media y durante el Renacimiento.

La imagen del monarca entronizado es bastante habitual en la miniatura medieval, es el claro precedente de las xilografías renacentistas. En efecto, documentos y libros miniados, el más cercano precedente a los libros impresos del s. XVI, también aportan interesantes ejemplos de la representación real a tener en cuenta. De hecho, cuando ilustran documentos, tienen la función de reafirmar la autoridad con que se expide; por ejemplo, el Tumbo A de la catedral de Santiago de Compostela. En este caso incluso se llega a hablar de "autentificación" del documento otorgado que aparece representado en forma de cartela. En este Tumbo se optó mayoritariamente por la imagen de majestad real con el monarca sedente, si bien aparecen también algunos retratos ecuestres (Fernando II, Alfonso IX y Alfonso X), una

\footnotetext{
${ }^{33}$ El monarca aparece entronado, portando los atributos propios de su dignidad regia, incluyendo la armadura de caballero. Sostiene, desenvainada y en alto, una espada, posible referencia, en este caso, a la justicia real. Apoyado en el suelo junto a él un escudo que lleva las armas de Castilla y León. La armadura la cubre parcialmente por un rico manto rojo con cenefas imitando piedras preciosas y sobre su larga cabellera se ha dispuesto el atributo regio por excelencia, la corona. El trono se completa con un rico tapiz brocado que resalta la figura del monarca. No hay pedestal a sus pies. Este monarca imberbe de larga cabellera y con ese tipo de brocado a su espalda puede estar siguiendo modelos estilísticos propios del de fines del s. XV y primeros años del s. XVI (de h. 1480-h. 1515), un modelo retardatario respecto al ejemplar copiado.
} 
tipología a la que también recurren las obras impresas $^{34}$. En ocasiones encontramos galerías de retratos reales más modestas desde un punto de vista artístico pero igualmente interesantes desde un punto de vista iconográfico, como en Las Semblanzas de Reyes ${ }^{35}$.

Existen ejemplos más cercanos, como en el caso de los dibujos de la Genealogía de los Reyes de D. Alonso de Cartagena, conservada en la Biblioteca del Palacio Real, que muestra a los monarcas desde Atanarico hasta Enrique IV. Aparece representada la imagen en majestad del monarca, sedente en el trono y portando los atributos de su poder real: corona, cetro y, muy a menudo, la espada. También se le representa de pie y, por supuesto, se pueden localizar algunos retratos ecuestres regios. Incluso se alude a su muerte trágica en algún caso. En estos dibujos los monarcas pueden aparecer acompañados de esposas e hijos. Isabel Mateo vincula estos dibujos con el pintor Jorge Inglés, h. $1460^{36}$.

${ }^{34}$ Sobre los retratos reales del Tumbo A y su significación, M. A. CASTIÑEIRAS GONZÁLEZ, “Poder, memoria y olvido: La Galería de retratos regios en el Tumbo A de la Catedral de Santiago (1129-1134)", Quintana, $n^{\circ}$ 1, 2002, pp. 187-196, especialmente p. 188; D. NOGALES RINCÓN, “Las series iconográficas de la realeza castellano-leonesa (siglos XII-XV)", en M. A. LADERO QUESADA, (coord.), Estudios de Genealogía, Heráldica y Nobiliaria, Madrid, 2006, pp. 81-111, especialmente pp. 99-101; R. SÁNCHEZ AMEIJEIRAS, "Sobre las modalidades y funciones de las imágenes en el Tumbo A", en M. C. DÍAZ Y DÍAZ (coord.), Tumbo A, Madrid, 2008, pp. 143-216.

${ }^{35}$ BNE, ms. 7415. R. M. RODRÍGUEZ PORTO, “María de Molina y la educación de Alfonso XI: Las Semblanzas de Reyes del Ms. 7415 de la Biblioteca Nacional", Quintana, no 5, 2006, pp. 219-231.

${ }^{36}$ Sobre esta obra, E. TORMO Y MONZÓ, Las viejas series icónicas de los reyes de España, Madrid, 1917; E. RUIZ GARCÍA, "Avatares codicológicos de la Genealogía de los Reyes de España", Historia, Instituciones, Documentos, no 27, 2000, pp. 295-331; I. MATEO GÓMEZ, Sobre el autor de los dibujos de la Genealogía de los Reyes de D. Alonso de Cartagena, Burgos, 2005; D. NOGALES RINCÓN, “Cultura visual y genealogía en la corte regia de Castilla durante la segunda mitad del siglo XV", eSpania (en línea), no 11, 2011, consultado el 1 de abril de 2014. URL: http://e-spania.revues.org/20362.
No es sólo la miniatura; la imagen en majestad del rey era muy apropiada también para otras manifestaciones artísticas, como se puede apreciar en la escultura. Es un buen medio para la reafirmación del poder regio. En Castilla destacó sin duda la serie de la Sala de los Reyes del Alcázar de Segovia (1456-1458), con los retratos de los monarcas desde Pelayo hasta Enrique IV. Se destruyeron en el incendio de 1862, pero son varias las fuentes para conocerlas. Estaba compuesta por 34 estatuas sedentes, coronadas y portando cetro y pomo en las manos ${ }^{37}$. Este último elemento lo podemos encontrar en numerosas representaciones regias medievales, pero en el caso de las ilustraciones de las Crónicas impresas del s. XVI conservadas en la BUO no siempre aparece. En ese sentido destacaría la portada de la Crónica de Alfonso X (Valladolid, 1554), un dinámico y corpulento monarca coronado, con el orbe y sosteniendo una gran espada; aunque está de pie, lo está sobre el estrado del trono ${ }^{38}$.

Durante la Edad Media se aprecian algunas imágenes en las artes figurativas claramente inspiradas en los sellos reales ${ }^{39}$. La

37 Sobre esta destacada serie iconográfica, entre otras publicaciones, cabe citar, F. COLLAR DE CÁCERES, "En torno al Libro de Retratos de los Reyes de Hernando de Ávila", Boletín del Museo del Prado, no 10, 1983, pp. 7-35; F. VILLASEÑOR, “La legitimación del poder real...", especialmente. p. 148 o D. NOGALES RINCÓN, “Cultura visual....".

\section{${ }^{38} \mathrm{BUO}, \mathrm{CGR}-454$}

${ }^{39}$ Martínez de Aguirre señala como ejemplo las claves de bóveda de la parroquia de la Asunción de Miranda de Arga y de la sacristía de Santo Domingo de Estella (s. XIII), que luego serán seguidas por numerosos ejemplos a lo largo del reino. Los monarcas de la casa de Champaña optaron por la imagen ecuestre, más frecuente en los reinos peninsulares durante el s. XIII que la imagen mayestática sedente. No obstante, el autor, al hablar de estas claves señala que se escoge el tipo anglofrancés (que muestra el flanco derecho) en lugar del mediterráneo (que muestra el flanco izquierdo) propio de los monarcas navarros anteriores a la Casa de Champaña, Sancho VI el Sabio y Sancho VII el Fuerte. J. MARTÍNEZ DE AGUIRRE ALDAZ, "La imagen del rey en la figuración gótica", en Signos de identidad histórica para Navarra, Pamplona, 1996, pp. 375-386, especialmente p. 376. También F. MENÉNDEZ PIDAL, M. RAMOS, 
sigilografía nos ofrece también varios tipos de representaciones de los monarcas; una de las más destacadas es la del monarca en majestad, con la corona y el cetro. Pero no podemos olvidar los sellos que muestran las efigies ecuestres de los monarcas, a menudo portando espada. Estos sellos se pueden encontrar en Castilla en el reinado de Alfonso VIII o Alfonso IX, por ejemplo, y posteriormente en sellos como los de Fernando III, Fernando IV, Alfonso XI, Pedro I o Enrique $\mathrm{III}^{40}$. La figura ecuestre del monarca coronado también se podía encontrar en sellos de otros reinos peninsulares, como es el caso del Reino de Navarra.

En efecto, el tipo del monarca a caballo es uno de las más representados en estas crónicas impresas en el siglo XVI. Son muchas las portadas de las crónicas, tanto principales como portadas internas, que nos muestran la imagen de un jinete. De hecho, en un mismo libro pueden aparecer varias imágenes ecuestres diferentes. Es una imagen convencional del monarca que también es caballero. Como se ha mencionado, los precedentes se pueden observar tanto en la miniatura como en la sigilografía, en relieves etc.

Además de los precedentes, también hay que tener presente el contexto histórico en que se imprimen esos libros: en el Renacimiento tuvo gran éxito el retrato ecuestre. En ese sentido, cabe recordar las xilografías de Jacob Cornelisz y Lucas van Leyden con

y E. OCHOA DE OLZA, Sellos medievales de Navarra. Estudio y corpus descriptivo, Pamplona, 1995; J. MARTÍNEZ DE AGUIRRE y F. MENÉNDEZ PIDAL, Emblemas heráldicos en el arte medieval navarro, Pamplona, 1996; o F. MENÉNDEZ PIDAL, "Emblemas heráldicos del rey" en Signos de identidad histórica para Navarra, Pamplona, 1996, pp. 351-360, donde se recoge la imagen del sello de Teobaldo I cabalgando al trote con armadura, escudo protegiendo su pecho, casco y espada desenvainada. No fue el único monarca en tener este tipo de sello ecuestre, también el sello de Juan II de Navarra muestra un caballero con cimera y corona, blandiendo espada y sosteniendo escudo.

${ }^{40} \mathrm{~T}$. F. RUIZ, "L'image du pouvoir à travers les sceaux de la monarchie castillane», en Génesis medieval del estado moderno: Castilla y Navarra (1250-1370), Valladolid, 1987, pp. 217-227. las series que representan a los condes de Holanda, el primero, y a reyes, príncipes y personajes antiguos destacados, como Alejandro Magno o Héctor, el segundo. Todos ellos aparecen a caballo, en lo que recuerda a procesiones triunfales. En la serie de Leyden llevan airosos penachos de plumas que recuerdan a los de las portadas de Cromberger, pero con mayor complejidad y calidad. Silver, al hablar de estas series con personajes ilustres de la Antigüedad y condes históricos holandeses, señala que se pueden poner en relación con un momento de optimismo ante la figura de Carlos de Habsburgo que ostenta tanto el título de Conde de Holanda como de Rey de España a partir de $1515-1516^{41}$. Son series que, sin duda, responden al gusto de los cortesanos por los modelos caballerescos.

Dentro de las imágenes regias ecuestres del conjunto de crónicas conservadas en Oviedo, una de las más destacadas es la que aparece en la Crónica de Juan II de 1517 (Fig. 4$)^{42}$. No es una portada, sino una composición a folio completo: el monarca a caballo aparece bajo una tracería gótica y flanqueado por retratos de medio cuerpo en hornacinas, la mayoría de ellos bustos de familiares con un papel destacado en su vida. El monarca lleva armadura y corona, sostiene con una mano el bastón de mando y con la otra sujeta con firmeza las riendas de su caballo en corveta. Su silueta nos recuerda a algunas representaciones ecuestres cuatrocentistas italianas, salvo por los encuadres gotizantes. La disposición de esta imagen, a modo de retablo, trae a la memoria otro ejemplar destacado de la literatura narrativa medieval, el manuscrito de la $\mathrm{Ge}$ nealogía de los Reyes de Alonso de Cartagena por ejemplo, las de D. Fernando I o D. Fernando

${ }^{41}$ L. SILVER, "Blijde Uitgave: Early Dutch Large Woodcut Ensembles and Politics", en Florissant tot de Kunstgeschiedenis der Nederlanden (15de-17de eeuw), Liber Amicorum Carl Van de Velde, Brussel, 2005, pp. 65-77, especialmente p. 72 .

${ }^{42} \mathrm{BUO}, \mathrm{CGR}-476$, en la página anterior al inicio de la Crónica de Juan II. 


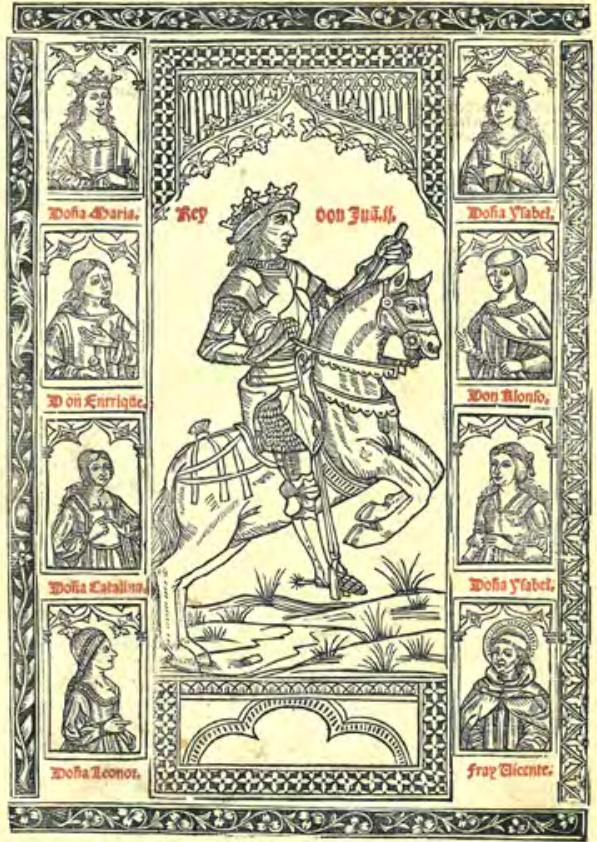

- Fig. 4. Fernán Pérez de Guzmán. Crónica del Serenísimo Rey Juan II, impresa por Arnao Guillén de Brocar, Logroño, 1517. Biblioteca de la Universidad de Oviedo, Signatura CGR-476. Foto BUO.

III ${ }^{43}$. Checa Cremades, al hablar de esta ilustración, se refiere no sólo a la imagen del rey como caballero, sino también a la idea dinástica a través de la presencia de las efigies de esposas e hijos ${ }^{44}$.

En la Crónica del Serenísimo Rey Juan II impresa en Sevilla en 1543, encontramos

${ }^{43}$ Madrid, Real Biblioteca, II/3009. E. TORMO MONZÓ, Op. cit., pp. 219-239; I. MATEO GÓMEZ, Op. cit., especialmente pp. 51 y 52; J. YARZA LUACES, “La imagen del rey y la imagen del noble...", especialmente pp. 277-278; F. VILLASEÑOR SEBASTIÁN, El libro iluminado en Castilla durante la segunda mitad del s. XV, Segovia, 2009.

${ }^{44} \mathrm{~F}$. CHECA CREMADES, “La imagen impresa en el Renacimiento y el Manierismo", en El Grabado en España (siglos XV al XVIII), vol. XXXI de "Summa Artis", Madrid, 1987, p. 102. Las figuras de la parte superior aparecen coronadas y se identifican con Dña. María y Dña. Isabel, las dos esposas de Juan II, y bajo cada una de ellas sus hijos. En el caso de la columna de la derecha, al tener dos hijos de ese matrimonio no se mantiene la simetría y se ha dispuesto la figura del santo Fray Vicente Ferrer.

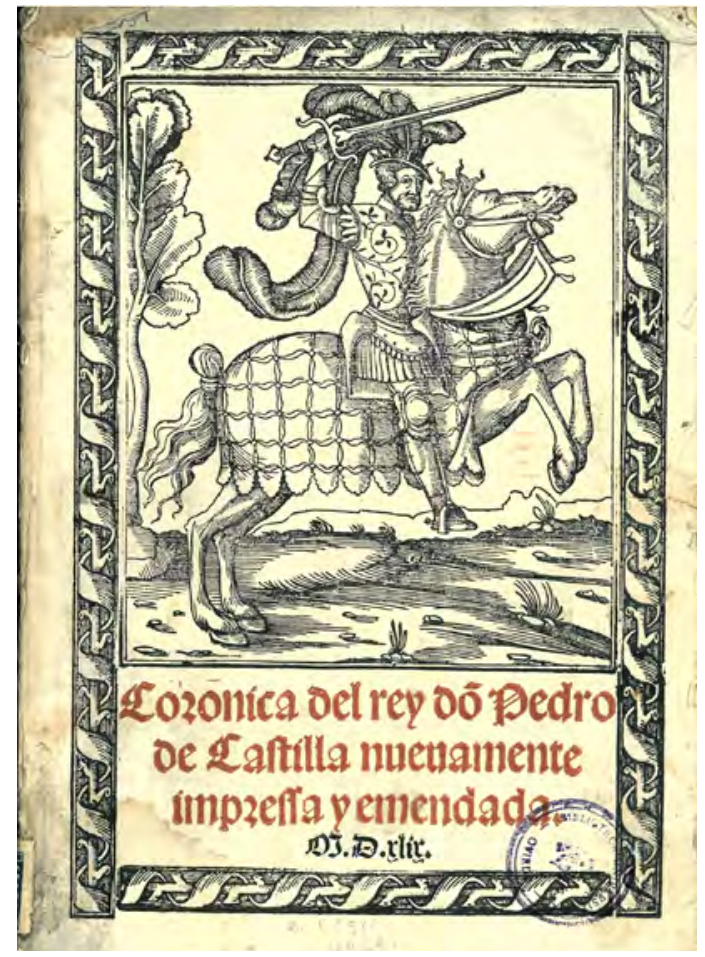

- Fig. 5. Pedro López de Ayala. Crónicas Reales, publicadas por Jacome Cromberger, Sevilla, 1549. Portada. Biblioteca de la Universidad de Oviedo, Signatura CGR-430. Foto BUO.

una representación ecuestre en la portada. El monarca va armado, lleva una cimera con corona y penacho de plumas. Se enmarca en una greca formada por una rama seca rodeada por una banda. Se puede relacionar esa portada con la de la novela de Caballería Florambel de Lucea, impresa en Sevilla en 1548 por Antón Álvarez. Este motivo del caballero se repetirá en otras obras.

Una de las más destacadas xilografías con el modelo ecuestre se puede encontrar en la Coronica del Rey D. Pedro impresa en los talleres de Cromberger en 1549 (Fig.5). Lo es por ser uno de los tacos más exitosos del momento, y no sólo en esa imprenta sevillana. Fue repetida en otras obras de los Cromberger, se puede citar como precedente la primera edición de esta crónica en 1542 y, lo que es más interesante, se reutilizó en las novelas de caballería Cirongilio de Tracia (1545) y el libro segundo de Espejo de caballerías (1549). Era una práctica habitual, no sólo en el taller de los Cromberger. Se repitieron tanto ilus- 
traciones como iniciales, y lo hicieron a lo largo de todo el siglo XVI, en sus diferentes generaciones. De esta manera, se rentabilizaba la inversión realizada inicialmente en la imprenta familiar. A ello cabe añadir la política de alquiler y venta de tacos que existía en la imprenta de la época. En efecto, podemos encontrar esta imagen reutilizada en otros talleres hispanos a lo largo del s. XVI, por ejemplo, y como señala Lucía Megías, en la Crónica del Rey D. Pedro de Andrés de Burgos (Sevilla, 1543), en una reedición del Amadís de Gaula realizada por Juan de Villaquirán y Pedro del Canto (Medina del Campo, 1545), con algunas variaciones en la Crónica de Alfonso XI impresa por Sebastián Martínez (Valladolid, 1551) -también conservada en la BUO-, así como en una portada interior de la cuarta parte del Florisel de Niquea impreso por Pierres de la Floresta (Zaragoza, 1568), por citar algunos ejemplos. Lucía Megías considera que se trata de una estrategia editorial para rentabilizar la inversión inicial ${ }^{45}$.

Sobre esta imagen de la portada de Cromberger, Checa Cremades señala que esta imagen convencional se encuentra en una obra impresa por mandato de Carlos I, lo que considera una prueba "del interés de la nueva dinastía por entroncar con sus raíces españolas" ${ }^{46}$. En este contexto tampoco debemos olvidar obras como el retrato de Carlos $V$ en la Batalla de Mühlberg, de Tiziano, donde se representa al emperador y al caballero cristiano. En efecto, Carlos ha sido considerado como un monarca que defiende ideales caballerescos, uno de los últimos ejemplos de los caballeros medievales ${ }^{47}$.

Aunque el taco xilográfico se hubiese realizado para una novela de caballerías en

${ }^{45}$ J. M. LUCÍA MEGÍAS, Op. cit., pp. 53 y 54, 146 y $175-176$

${ }^{46}$ F. CHECA CREMADES, Op. cit., pp. 105-106.

${ }^{47}$ M. NÚÑEZ RODRÍGUEZ, “Cuando la historia se hace mito", Quintana, no 1, 2002, pp. 41-69, especialmente p. 42. S. FERINO-PADGEN, "La imagen ideal y natural del poder: los retratos de Carlos V por Tiziano", en F. CHECA CREMADES, (dir.), Carolus, Madrid, 2000, pp. 67-79, especialmente pp. 76-77. su primera función, ¿por qué no aprovecharlo para una crónica real?; no con un carácter arcaizante ni medievalizante, sino dentro de una iconografía perfectamente asentada que hundía sus raíces varios siglos atrás, como bien muestran, por ejemplo, las miniaturas o los sellos reales hispanos.

Si analizamos otras imágenes ecuestres conservadas en estas crónicas de la BUO se puede observar que algunas de ellas no hacen la mínima alusión a la dignidad regia del monarca, más allá de su aspecto de caballero. Es el caso de la imagen de dos portadas interiores de la Crónica de Alfonso XI publicada por Sebastián Martínez en Valladolid en 1551 y dos crónicas publicadas por Porralis en Pamplona en 1591: la Crónica de D. Pedro del Canciller Ayala, tanto en la portada principal como en las interiores, y la Crónica de D. Juan II. En otros casos se muestra un ligero indicio de corona en el yelmo o en el tocado con que aparece la figura. El estilo de todas estas xilografías varía en gran medida de unas a otras imágenes ecuestres, pero todas ellas presentan gran similitud en cuanto a su iconografía: un jinete a lomos de un caballo que va a ritmo más o menos veloz, vestido con armadura y normalmente con yelmo, y sosteniendo algún tipo de arma.

En un proceso que se aprecia ya en época del emperador Carlos V y se intensifica en la época del rey Felipe II, asistimos a una evolución en el retrato regio. Las representaciones regias en las crónicas objeto de estudio en este artículo van a quedar lejos ya de los retratos de estado, aunque la importante difusión de este género literario en la España del siglo XVI sea vista con interés por parte del monarca. En ese sentido es muy significativa la ilustración de la obra de Garibay. Cronológicamente está muy cercana a algunas ediciones aquí estudiadas, pero sus magníficos grabados se centran en el elemento heráldico. El único retrato regio que acompaña al texto es el del futuro Felipe III, que responde al modelo de retrato de corte propio del reinado de Felipe II, fidedigno y acompañado de los atributos de su posición. 


\section{LA PRESENCIA DE LA RELIGIÓN EN LAS CRÓNICAS}

En estas Crónicas aparecen también escenas o figuras religiosas en iniciales figurativas, en remates decorativos, aunque también hay una excelente escena independiente que muestra el Calvario en la Crónica de Juan $I^{48}$.

Este magnífico Calvario va firmado con las iniciales ID antes de comenzar el texto de la crónica. Corresponden al grabador Juan de Vingles. La escena es muy sencilla, con Cristo entre la Virgen y san Juan en un despejado paisaje con Jerusalén al fondo. Sigue modelos propios del norte de Europa, como se aprecia por el tratamiento del paño de pureza de Cristo o los plegados de las indumentarias. Se puede hablar de un vínculo estrecho entre las crónicas reales y las representaciones religiosas, lo que queda afianzado con esas numerosas iniciales con figuración religiosa.

En esta edición, entre las iniciales figurativas, se pueden citar, por su calidad, la P con el Nacimiento de Cristo, la que inicia esta Crónica, la I con san Juan Evangelista en el capítulo VI, la M con la pareja de santas mártires, entre otras. Hay una inicial, repetida, que destaca especialmente por el tema tratado ya que representa en una $\mathrm{E}$ a Cristo de pie, con túnica, bendiciendo y con el orbe en la mano (capítulo CXX, entre otros). No parece que pueda considerarse mera casualidad que aparezca en una crónica en la que también se han dispuesto iniciales con monarcas vestidos de época, de pie o sedentes, con insignias de poder, entre ellas, el orbe. Precisamente esta inicial la volvemos a encontrar en otra edición, la Crónica de Juan II (Andrés de Burgos, Sevilla, 1543) ${ }^{49}$.

Es evidente que ya en la Edad Media castellana se podía percibir una clara vinculación de lo religioso con el poder político, es un modo de legitimación de la autoridad re-

\footnotetext{
${ }^{48} \mathrm{BUO}, \mathrm{CGR}-476$.

${ }^{49} \mathrm{BUO}, \mathrm{CGR}-457$, repetida en varias ocasiones.
}

gia. La presencia de estas iniciales en las que aparece Cristo con algunos de los atributos regios podría entenderse como la imagen del verdadero rey, tal y como se considera a Dios en la teología política medieval. Cristo es un modelo para los monarcas. Más aún, algunos autores medievales sostuvieron la idea de Rex imago Christi ${ }^{50}$. Además, dentro de las funciones del monarca se entendía que estaba la de defender a la cristiandad y no sólo durante los siglos medievales; recordemos que estas crónicas se han publicado en el siglo XVI y la postura que Carlos I y Felipe II sostenían era la de apoyar a la Iglesia Católica. Por tanto, no es extraño el uso de escenas e iniciales con motivos religiosos en estas obras de historia y exaltación monárquica, si bien no es desdeñable el peso de las razones prácticas del día a día de la imprenta y su necesidad de reducir costes mediante reutilización de tacos.

En ese contexto, una de las escenas religiosas más vinculadas con la monarquía y los gobernantes es la escena del Juicio Final, un tema que se puede poner en relación con una de las funciones del monarca: impartir justicia. Se puede encontrar en el remate ornamental de las primeras palabras de la Crónica de Alfonso XI ${ }^{51}$. También lo es la escena de la Adoración de los Reyes Magos que encontramos en una inicial E en la Crónica de D. Pedro de 1549, una xilografía con un tratamiento miniaturístico (Fig. 6) ${ }^{52}$.

${ }^{50}$ J. M. NIETO SORIA, Fundamentos ideológicos del poder real en Castilla (Siglos XIII-XVI), Madrid, 1988, p. 46-47, 49 y Orígenes de la monarquía hispánica: Propaganda y legitimación (ca. 1400-1520), Madrid, 1999, especialmente pp. 32-38. E. H. KANTOROWICZ, Op. cit., pp. 58-59, у р. 68.

${ }^{51}$ BUO, CGR-454, fol. Vv.

${ }^{52}$ BUO, CGR-430, fol. II r. A nuestra izquierda, en un lateral, aparece la Virgen sentada, con aureola, sosteniendo en su regazo al Niño, ante Él se arrodilla el rey más anciano, Melchor, ofreciéndole su presente y sin portar la corona. Entre los dos, de pie y en segundo plano, se dispone Gaspar, con corona y presente en la mano, y detrás de Melchor, también de pie aparece Baltasar, que lleva un tocado con corona y es joven. Es evidente que se ha recurrido a tratar el tema de las tres edades y no el de las razas, pues los rasgos de Baltasar no corresponden con rasgos africanos. Detrás de 


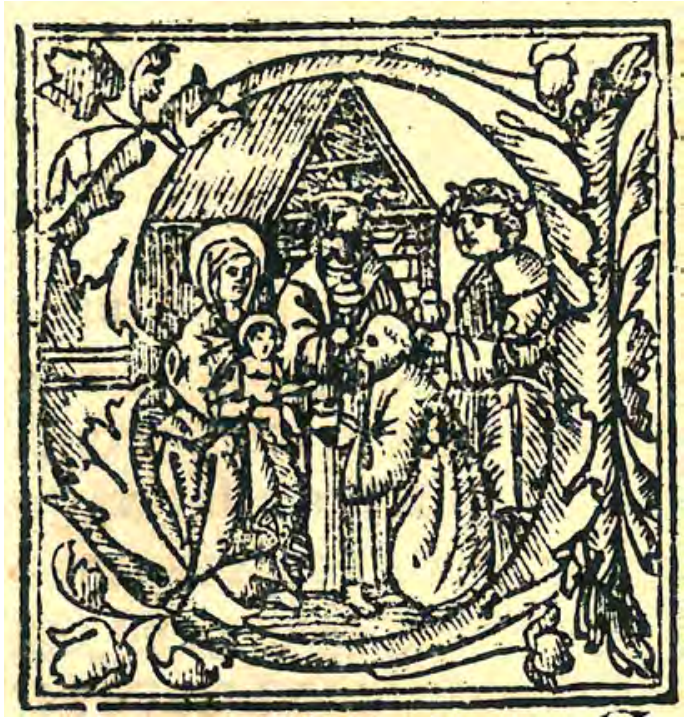

- Fig. 6. Pedro López de Ayala. Crónicas Reales, publicadas por Jacome Cromberger, Sevilla, 1549. Inicial. Biblioteca de la Universidad de Oviedo, Signatura CGR-430. Foto BUO.

Se trata de una escena muy bella y no está especialmente emborronada. Es muy interesante la elección del tema de la Adoración de los Reyes Magos para iniciar justamente una crónica de un monarca cristiano. La búsqueda de vínculos de las monarquías europeas con figuras de la realeza que aparecen en la Biblia es bastante conocida; en ese sentido se puede citar la disposición de las estatuascolumna de los Reyes de Judá en las jambas de la abadía de Saint-Denis.

Otra inicial figurativa destacada es la E con la Anunciación de las Crónicas del Canciller Ayala publicadas por Porralis en $1591^{53}$. En este ejemplar se encuentran sobre todo iniciales figurativas hagiográficas, algunas de especial belleza como la A de san Antón en el momento de la tentación, la $\mathrm{E}$ con tres santos mártires, uno de ellos san Sebastián recibiendo las flechas, la V con el arcángel san Miguel venciendo al demonio, entre otras. Es evidente que se ha reutilizado el juego para

este grupo principal aparece un establo estrecho y de techumbre muy inclinada. Ha desaparecido la figura de san José tradicional en esta escena posiblemente por el escaso espacio con que contaba el grabador. $(5.2 \times 5 \mathrm{~cm})$.

${ }^{53}$ BUO, CGR-429. una obra de carácter secular, concretamente del género histórico. Es el mismo juego que utiliza el impresor Porralis para otra obra que sale de sus prensas, la Crónica de Juan II de Pérez de Guzmán (Pamplona, 1591) ${ }^{54}$.

Claramente reaprovechadas son las iniciales que aparecen en la Crónica de Fernando III, $1568^{55}$, algunas de ellas no son de calidad y la imagen aparece borrosa, dificultando la identificación, pero en las que se puede reconocer las escenas se aprecia que son motivos tomados de la Biblia, varios de ellos del Antiguo Testamento, como los trabajos de Adán y Eva en la inicial C, el Diluvio Universal en la letra D, o la escala de Jacob en la inicial L, por citar algunas de ellas. Es evidente que no tienen ninguna relación con el texto al que acompañan y es un claro ejemplo de reutilización de juegos destacados de iniciales en obras de contenido diferente.

\section{CONCLUSIONES}

Tras el análisis de la iconografía de este conjunto de crónicas reales castellanas impresas en el siglo XVI y conservadas en la Biblioteca Universitaria de Oviedo se puede observar que no suponen una novedad respecto a la iconografía regia encontrada en libros, documentos, sellos, pinturas o esculturas medievales. Simplemente, se ha empleado otra técnica para su plasmación: la xilografía.

A través de ellas se refleja una realidad de la imprenta hispana del momento, el reaprovechamiento de tacos xilográficos para abaratar costes, tanto en ilustraciones como en iniciales decorativas, conforme avanza el siglo. Son motivos que se encuentran en libros de caballerías, libros religiosos, etc. En ocasiones ese reaprovechamiento es muy lógico por los contenidos a los que acompañan o el simbolismo que puedan aportar; en otras ocasiones es una mera razón circunstancial.

Aunque dedicadas a los monarcas o promovidas por ellos, estas Crónicas no

\footnotetext{
${ }^{54} \mathrm{BUO}, \mathrm{CGR}-460$.

${ }^{55}$ BUO, CGR-444.
} 
eran obras destinadas al monarca, sino a su difusión entre sectores de cierto nivel socioeconómico y cultural de la época. La imprenta fue un aliado poderoso en ese objetivo al abaratar los costes.

La presencia de otras crónicas publicadas en los territorios de la antigua Corona de Aragón, de obras que recogen hechos de personajes ilustres o de crónicas extranjeras en estos fondos bibliográficos universitarios, contribuyen a un mejor conocimiento de la decoración del libro impreso en la época y ofrecen un complemento de gran interés para el estudio de las crónicas reales castellanas. 